\title{
Native ligand carbonization renders common platinum nanoparticles highly durable for electrocatalytic oxygen reduction: annealing temperature matters
}

\section{Zhicheng Li \\ Fudan University \\ Jinxiang Zou \\ Fudan University \\ Xiangyun Xi \\ Fudan University \\ Pengshuo Fan \\ Fudan University \\ Ye Peng \\ Foshan University \\ Dustin Banham \\ Foshan University \\ Dong Yang}

Fudan University https://orcid.org/0000-0001-6527-1272

Angang Dong ( $\nabla$ agdong@fudan.edu.cn )

Fudan University https://orcid.org/0000-0002-9677-8778

Article

Keywords:

Posted Date: March 7th, 2022

DOI: https://doi.org/10.21203/rs.3.rs-1404028/v1

License: (c) (i) This work is licensed under a Creative Commons Attribution 4.0 International License. Read Full License

Version of Record: A version of this preprint was published at Advanced Materials on April 14th, 2022. See the published version at https://doi.org/10.1002/adma.202202743. 



\title{
Native ligand carbonization renders common platinum nanoparticles highly durable for electrocatalytic oxygen reduction: annealing temperature matters
}

\begin{abstract}
:
Monodisperse nanoparticles have attracted great attention in fundamental and applied research. Current protocols for the synthesis of monodisperse nanoparticles typically involve hydrocarbon molecules as surface-capping ligands. Utilizing platinum (Pt)based nanoparticles for the oxygen reduction reaction (ORR), however, hydrocarbon ligands must be removed in order to expose the surface sites. Here, highly active and durable Pt catalysts are realized without removing the ligands; instead, the native surface ligands are directly converted into uniform, bilayered graphitic shells conformally coated on individual Pt nanoparticles by simple thermal annealing. Strikingly, the annealing temperature is found to be a critical factor dictating the ORR performance of Pt catalysts. Pt nanoparticles thermally treated at $500{ }^{\circ} \mathrm{C}$ show a very poor ORR activity, whereas those annealed at $700{ }^{\circ} \mathrm{C}$ become highly active along with exceptional stability. In-depth characterization reveals that thermal treatment from 500 to $700{ }^{\circ} \mathrm{C}$ triggers the subtle structural reconstruction of carbon shells through graphitization, gradually opening up the porosity without affecting the carbon shell thickness. Additionally, the ligand-derived graphitic shells can effectively prevent Pt nanoparticles from detachment, agglomeration, and dissolution while largely maintaining the accessibility of surface sites. As a result, such graphitic-shell-coated Pt catalysts can exhibit superior long-term stability, largely retaining the activity after
\end{abstract}


20,000 accelerated durability test cycles in a membrane electrode assembly. Moreover, this ligand carbonization strategy is amenable to Pt-based alloy nanoparticles and can further be extended to modify commercial $\mathrm{Pt} / \mathrm{C}$ catalysts with substantially enhanced durability. Our work shows that boosting the ORR performance of common $\mathrm{Pt}$ nanoparticles is certainly possible by harnessing the native surface ligands, thus offering a robust approach of designing highly durable catalysts for proton-exchange membrane fuel cells.

\section{Introduction}

As one of the most promising energy conversion devices, proton-exchange membrane fuel cells (PEMFCs) have been attracting much attention for many years ${ }^{1-3}$. It is known that the sluggish cathodic kinetics of the oxygen reduction reaction (ORR) greatly limits the conversion efficiency of PEMFCs ${ }^{4,5}$. To date, Pt (or Pt-based alloys) nanoparticles (NPs) loaded on a carbon support are still the most promising ORR catalysts due to their intrinsically high activity ${ }^{6}$ However, Pt catalysts typically suffer from the poor durability during long-term operation ${ }^{7}$, which is one of the critical issues hampering the widespread applications of PEMFCs ${ }^{8,9}$. Under the harsh operation conditions of PEMFCs, Pt catalysts can easily lose the electrochemical surface area (ECSA) due to multiple reasons, including the Ostwald ripening and agglomeration of $\mathrm{Pt} \mathrm{NPs}^{8,10}$, detachment of Pt NPs from the carbon support ${ }^{11}$, dissolution of $\mathrm{Pt}^{12}$, and corrosion of the carbon support ${ }^{13}$.

In the past few decades, many efforts have been dedicated to addressing the stability issue of Pt catalysts ${ }^{14-16}$. Coating Pt NPs with a porous and electrochemically 
stable encapsulating layer has proven to be a promising approach to enhance the ORR durability $^{17}$, as this can effectively prevent the agglomeration of NPs while simultaneously suppressing the dissolution of $\mathrm{Pt}$, due to the combined barrier and confinement effects ${ }^{18}$. Among various encapsulating materials explored, carbon shows great promise because of its high electrical conductivity, electrochemical stability, and relatively benign corrosion products ${ }^{18,19}$. For instance, Kwon et al. reported the synthesis of carbon-coated Pt NPs on carbon nanofibers using Pt-aniline complexes as the precursor ${ }^{18}$. Hyeon et al. presented the synthesis of intermetallic ordered FePt NPs coated with N-doped carbon shells derived from polydopamine, where the carbon shell thickness can be tuned by controlling the polymerization duration ${ }^{20}$. Indeed, these carbon-coating strategies can dramatically enhance the durability of ORR catalysts as indicated by both rotating disk electrode (RDE) and membrane electrode assembly (MEA) tests. Despite the improved durability, the presence of a protective layer at the particle surface can inevitably block some surface sites and restrict mass transport ${ }^{21}$, thereby adversely influencing the catalytic performance of Pt catalysts. Therefore, the ability to fine-tune the thickness and microstructure of carbon shells to achieve an optimized tradeoff between activity and durability, although challenging, is critical to taking full advantage of this carbon-coating strategy ${ }^{19,22}$. Moreover, most previously reported carbon-coating methods involve the incorporation of a foreign species (usually a polymer) as the carbon source ${ }^{20,21}$, which does not necessarily have a preferential affinity to Pt, thus making it challenging to achieve complete and uniform carbon shells coated on individual NPs. 
On the other hand, exploiting monodisperse Pt NPs is an effective means to inhibit Ostwald ripening during $\mathrm{ORR}^{8,23-25}$. To date, monodisperse NPs are typically obtained by colloidal synthesis, involving the use of hydrocarbon ligands to control the nucleation and growth kinetics of NPs. ${ }^{24}$ Typical ligands include oleylamine (OAm) and oleic acid $(\mathrm{OA})^{24-26}$. The as-synthesized, ligand-capped NPs are highly soluble in nonpolar solvents ${ }^{25}$, which is beneficial for subsequent solution processing. Despite these advantages, however, these long-chain organic ligands are highly insulating and can act as a dense barrier to restrict the accessibility of $\mathrm{NPs}^{27}$, thus having a detrimental influence on their catalytic applications. As a consequence, to harness Pt NPs as ORR catalysts, the native surface ligands have to be replaced or removed in order to expose the surface $\operatorname{sites}^{28,29}$. To this end, a number of techniques have been developed to treat Pt NPs, such as multiple cycles of washing with non-solvents ${ }^{30}, \mathrm{UV}$-ozone cleaning ${ }^{24}$, and ligand exchange with small molecular (or ionic) species ${ }^{25,31}$. Alternatively, the hydrocarbon ligands can also be removed by calcination in air $^{32}$. Although Pt NPs become active toward the ORR upon post surface treatment, the catalytic performance depends highly on the surface treatment methods. In addition, whether the native ligands are completely removed by these treatment methods remains an open question ${ }^{25}$, which accounts for the performance inconsistency commonly encountered.

In contrast to previous methods where attempts are made explicitly to remove or replace the surface ligands ${ }^{24-32}$, we report herein that the native ligands can be exploited to render common Pt NPs highly active and durable for the ORR. We show that simple thermal annealing can convert the hydrocarbon ligands into uniform, ultrathin graphitic 
layers conformally coated on individual Pt particles, without sacrificing the size monodispersity of NPs. We highlight that the annealing temperature has a profound influence on the ORR performance of the resulting carbon-coated Pt catalysts. Specifically, thermal treatment of Pt NPs at $500{ }^{\circ} \mathrm{C}$ leads to highly dense carbon shells severely restricting the accessibility of surface sites, whereas increasing the annealing temperature triggers the reconstruction of carbon shells through graphitization, gradually opening up the transport channels for accessing the particle surface. In particular, thermal annealing of Pt NPs at $700{ }^{\circ} \mathrm{C}$ leads to bilayered graphitic shells with optimized porosity, yielding graphitic-shell-coated Pt catalysts with a superior ORR activity and stability. Importantly, this in situ ligand carbonization strategy is robust and broadly applicable for all Pt or Pt-based alloy NPs and can be further extended to boost the durability of commercial $\mathrm{Pt} / \mathrm{C}$ catalysts. Our work demonstrates that the native surface ligands, previously considered detrimental for catalytic applications, can be harnessed to develop highly active and stable ORR catalysts for high-performance PEMFCs.

\section{Results and Discussion}

\subsection{Synthesis and characterization of graphitic-shell-coated Pt catalysts}

Scheme 1 illustrates the preparation of the graphitic-shell-coated Pt catalysts through in situ ligand carbonization. Monodisperse Pt NPs ( $\sim 5 \mathrm{~nm}$ in diameter) are synthesized via a standard thermal decomposition approach using OAm and OA as the capping ligands ${ }^{33}$. Prior to ligand carbonization, the as-synthesized Pt NPs are first loaded onto a carbon support such as Ketjenblack (KB) by sonication (Pt@KB). Subsequently, the 
$\mathrm{Pt} @ \mathrm{~KB}$ is subjected to thermal annealing in a $\mathrm{N}_{2}$ atmosphere at $500{ }^{\circ} \mathrm{C}$ for $1 \mathrm{~h}$, which converts the OAm/OA ligands into conformal carbon shells. To obtain graphitic-shellcoated Pt catalysts, such carbon-coated Pt NPs are further annealed at various temperatures $\left(600-800^{\circ} \mathrm{C}\right)$ for another $1 \mathrm{~h}$, which triggers the reconstruction of carbon shells to afford porous, graphitic layers ${ }^{34}$. The resulting catalyst is labeled with Pt-T, where $\mathrm{T}$ is the annealing temperature. The typical Pt loading of Pt-T catalysts is $\sim 35$ wt.\%, determined by thermogravimetric analysis (TGA) and inductively-coupled plasma mass spectrometry (ICP-MS).

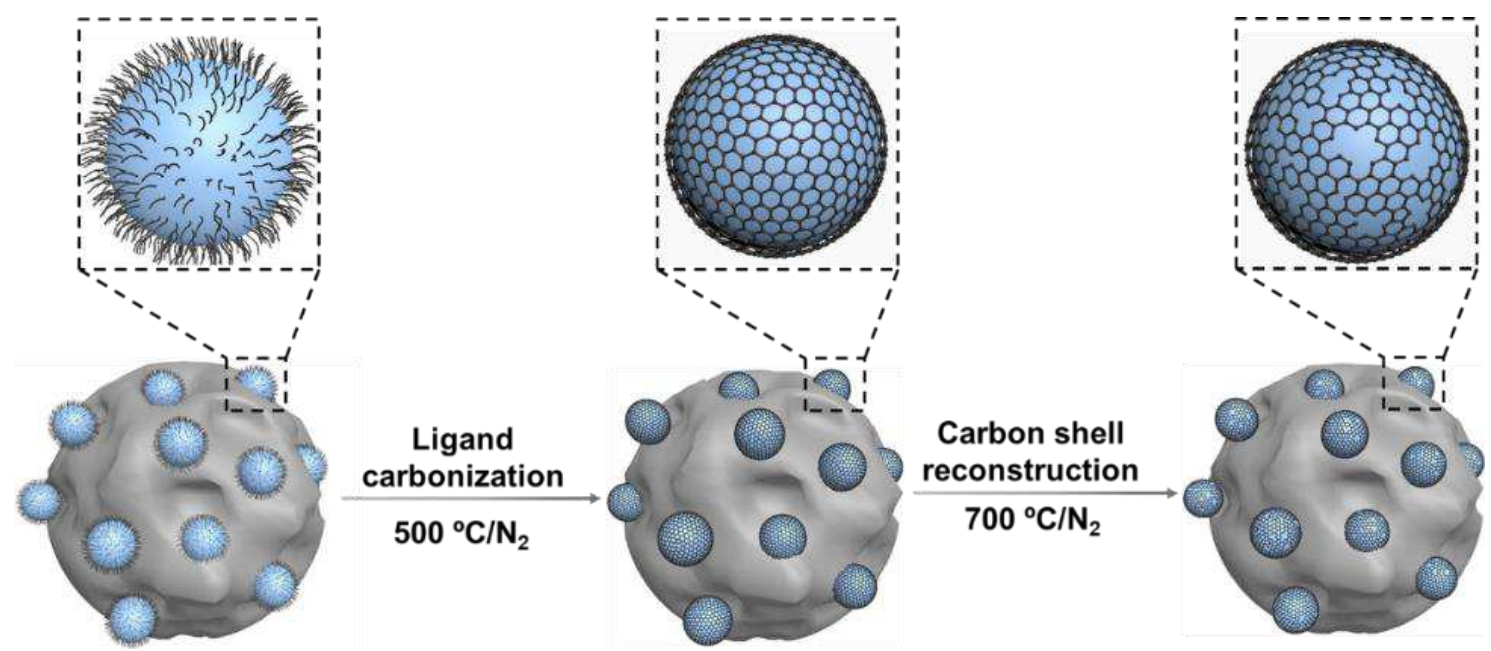

Scheme 1. Schematic illustration of the synthesis of graphitic-shell-coated Pt catalysts through native ligand carbonization.

Supplementary Fig. 1 shows a transmission electron microscopy (TEM) image of the as-synthesized $5 \mathrm{~nm}-\mathrm{Pt}$ NPs with narrow size distribution. The high-resolution TEM (HRTEM) image of Pt-500 (Fig. 1a) reveals the presence of a complete carbon shell conformally coated on each NP (Fig. 1e), presumably arising from the carbonization of the OAm/OA capping ligands. A closer inspection of the HRTEM images indicates that the carbon shells are quite uniform in thickness, with the majority comprising two carbon layers. TEM also reveals that such carbon-coated Pt NPs are 
highly sintering-resistant and can maintain their size upon thermal annealing up to 700 ${ }^{\circ} \mathrm{C}$ (Fig. 1a-c), although apparent particle agglomeration was observed when annealed at $800{ }^{\circ} \mathrm{C}$ (Fig. 1d). Notably, no substantial variation in carbon shell thickness was observed for Pt-600 and Pt-700 (Fig. 1f and 1g), whereas many Pt particles in Pt-800 are no longer coated by carbon shells (Fig. 1h). These results demonstrate that Pt NPs supported on $\mathrm{KB}$ can withstand thermal annealing without sacrificing the size monodispersity when the annealing temperature is below $700{ }^{\circ} \mathrm{C}$, which is remarkable considering the high Pt loading ( $\sim 35$ wt.\%). Presumably, the excellent thermal stability of the Pt NPs is attributed to the ligand-derived carbon shells, which effectively prevent the coarsening of NPs during thermal annealing. Control experiments show that the same Pt NPs loaded on KB, upon ligand removal by repeated washing with ethanol, underwent severe sintering when thermally treated at $700{ }^{\circ} \mathrm{C}$ (Supplementary Fig. 2). This illustrates the important role of the ligand-derived carbon shells in preventing the sintering of Pt NPs.
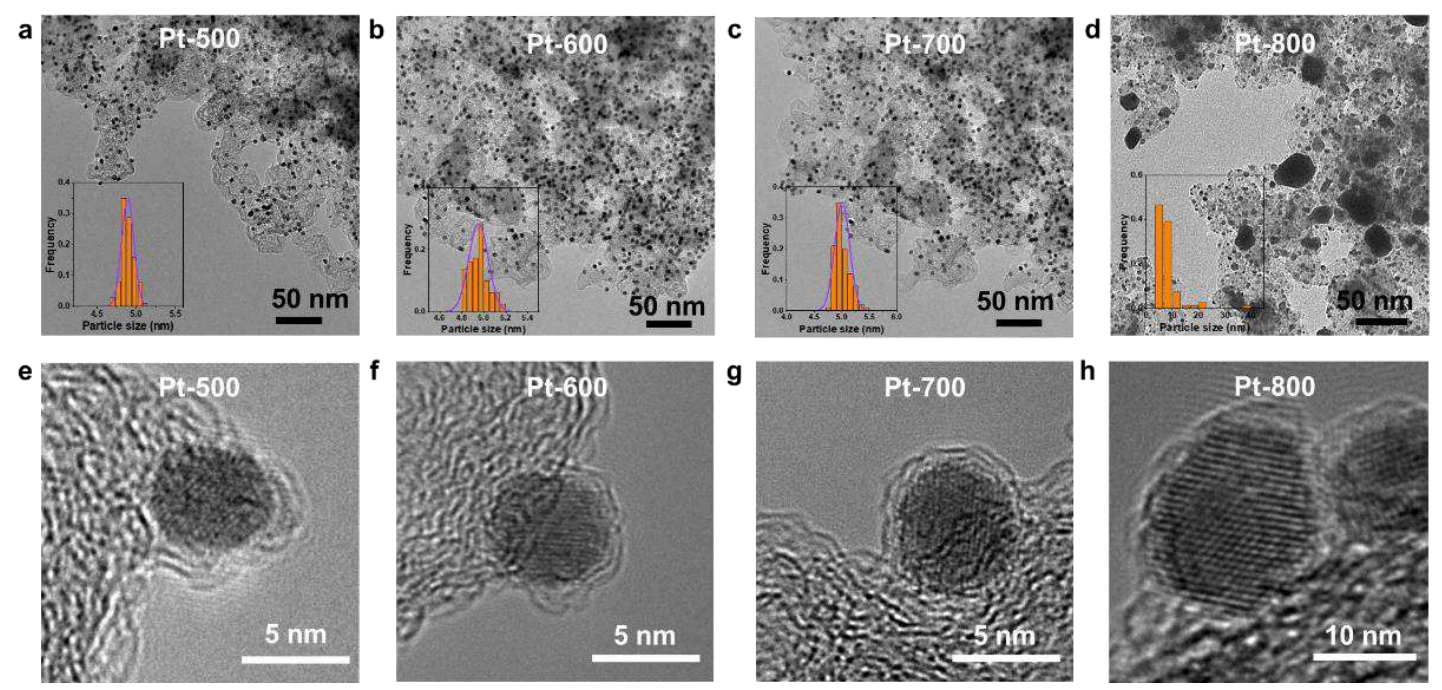

Fig. 1: (a-d) TEM images and the corresponding particle size distributions (inset) of various Pt-T catalysts. (e-h) HRTEM images of various Pt-T catalysts. 
The size variation of Pt NPs with respect to the annealing temperature was further investigated by X-ray diffraction (XRD). Fig. 2a shows the XRD patterns of various Pt-T catalysts, where the three major peaks located at $39.8^{\circ}, 46.3^{\circ}$, and $67.5^{\circ}$ were ascribed to the (111), (002), and (022) planes of Pt (JCPDS\# 96-101-1108) ${ }^{35}$. The crystalline size of Pt NPs, calculated based on the Scherrer equation ${ }^{36}$, was essentially unchanged from Pt-500 to Pt-700. The significantly reduced peak width of Pt-800 was consistent with the particle agglomeration at $800{ }^{\circ} \mathrm{C}$. To reveal the characteristics of the ligand-derived carbon shells, Raman spectra of Pt-500 and Pt-700 were comparatively analyzed. As shown in Supplementary Fig. 3, both Pt-500 and Pt-700 show the typical $\mathrm{D}$ and $\mathrm{G}$ bands at 1300 and $1590 \mathrm{~cm}^{-1}$, respectively, with the $I_{\mathrm{D}} / I_{\mathrm{G}}$ ratio decreasing from 1.32 to 1.01 , suggesting that the graphitization degree of Pt-T increases with the increased annealing temperature ${ }^{37}$. However, we note that the KB support may dominate the Raman signals of Pt-T, and therefore further characterization is needed to reliably evaluate the graphitization degree of carbon shells. As shown in Fig. 2b, the TGA curves of both Pt-500 and Pt-700 show the major weight loss from 300 to $450{ }^{\circ} \mathrm{C}$, which corresponds to the oxidation of the KB support. For Pt-500, an additional weight loss of $\sim 3.8 \mathrm{wt} . \%$ appears in the lower temperature region between 160 and $200{ }^{\circ} \mathrm{C}$ (indicated by the arrow in Fig. 2b). This weight loss, presumably ascribed to the oxidation of the less-graphitized carbon shells ${ }^{38,39}$, was not observed for Pt-700. This result suggests that as the annealing temperature increased from 500 to $700{ }^{\circ} \mathrm{C}$ the graphitization degree of carbon shells was increased to a level comparable to that of the KB support. 

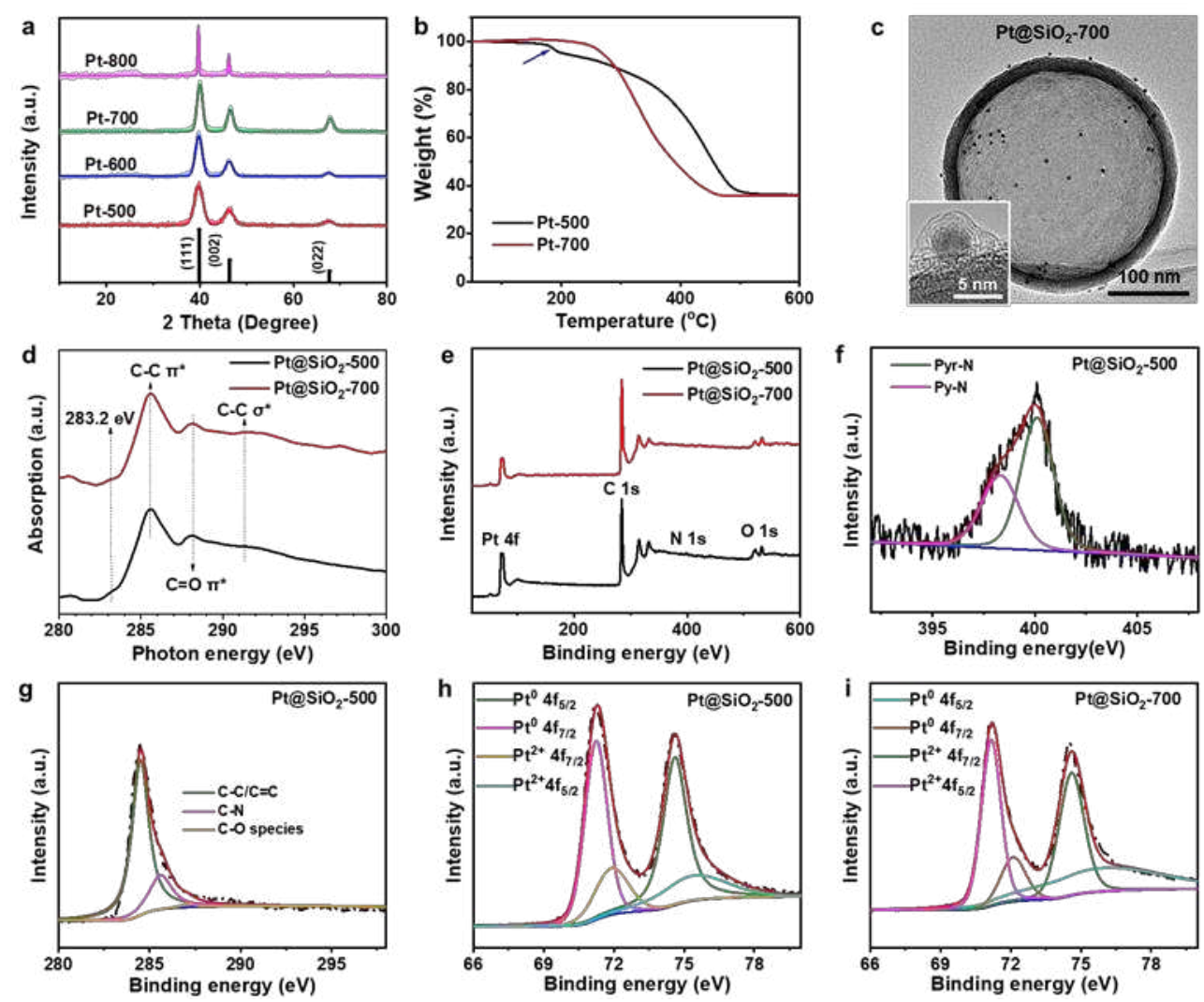

Fig. 2: (a) XRD patterns of various Pt-T catalysts. (b) TGA curves of Pt-500 and Pt700. The blue arrow indicates the weight loss attributed to the carbon shells in Pt-500. (c) TEM and HRTEM (inset) images of Pt@ $\mathrm{SiO}_{2}-700$. (d) C K-edge XANES spectra of $\mathrm{Pt} @ \mathrm{SiO}_{2}-500$ and $\mathrm{Pt} @ \mathrm{SiO}_{2}-700$. (e) XPS survey spectra of $\mathrm{Pt} @ \mathrm{SiO}_{2}-500$ and Pt@SiO $\mathrm{Si}_{2}$-700. (f) N 1s, (g) C 1s, and (h) Pt 4f XPS spectra of Pt@ $\mathrm{SiO}_{2}-500$; (i) Pt 4f XPS spectrum of Pt@ $\mathrm{SiO}_{2}-700$.

To verify that the carbon shell is transformed from the OAm/OA ligands rather than the unstable species in the carbon support ${ }^{40}$, Pt NPs were also loaded onto noncarbonaceous supports such as hollow $\mathrm{SiO}_{2}$ spheres followed by thermal annealing under otherwise identical conditions. The product was named as $\mathrm{Pt} @ \mathrm{SiO}_{2}-\mathrm{T}$, depending on the annealing temperature (i.e., $500-700{ }^{\circ} \mathrm{C}$ ). Similar to the Pt NPs loaded on KB, heat treatment of $\mathrm{Pt} @ \mathrm{SiO}_{2}$ also led to carbon-coated Pt NPs (Fig. 2c), thus confirming that the carbon shell indeed originates from the surface ligands. Moreover, the absence 
of carbon supports further allows us to disentangle the fine structural features of carbon shells with the varied annealing temperatures. Fig. 2d shows the C K-edge X-ray absorption near-edge structure (XANES) spectra of $\mathrm{Pt} @ \mathrm{SiO}_{2}-500$ and $\mathrm{Pt} @ \mathrm{SiO}_{2}-700$, where the characteristic $\pi-\pi^{*}(\sim 285 \mathrm{eV})$ and $\sigma-\sigma^{*}(\sim 291 \mathrm{eV})$ resonance peaks elucidate the typical graphene-like features exhibited by the ligand-derived carbon shells. For all $\mathrm{Pt} @ \mathrm{SiO}_{2}-\mathrm{T}$ samples, the resonance absorption peak at $288.3 \mathrm{eV}$ suggests the presence of heteroatoms (e.g., O) in carbon shells ${ }^{41}$. In addition, a weak shoulder at around 283.2 $\mathrm{eV}$ is also observed in both cases. This feature is attribute to the surface defects, such as dangling bonds and amorphous carbon ${ }^{42}$. With the increased annealing temperature, the pre-edge feature intensity of $\mathrm{Pt} @ \mathrm{SiO}_{2}-\mathrm{T}$ slightly increases, suggesting that more defect sites have been created in the carbon shells ${ }^{43}$.

The X-ray photoelectron spectroscopy (XPS) spectrum of Pt@SiO $2-500$ shows the presence of Pt, C, O, and N (Fig. 2e), where $\mathrm{N}$ atoms ( 2.3 at.\%) should originate from the OAm ligands. As indicated by the high-resolution N 1s spectrum (Fig. 2f), N mainly exists in the forms of pyridine $\mathrm{N}(\sim 398 \mathrm{eV})$ and pyrrole $\mathrm{N}(\sim 400 \mathrm{eV})$. The highresolution $\mathrm{C}$ 1s spectrum indicates the presence of $\mathrm{C}-\mathrm{N}$ species in carbon shells (Fig. $\mathbf{2 g})^{44}$, indicating that the native OAm ligands were converted into $\mathrm{N}$-doped carbon shells upon thermal annealing at $500{ }^{\circ} \mathrm{C}$. Notably, the N signals of Pt@ $\mathrm{SiO}_{2}-700$ were essentially undetectable by XPS (Fig. 2e), suggesting that thermal annealing at $700{ }^{\circ} \mathrm{C}$ nearly completely removed $\mathrm{N}$ atoms from carbon shells, in addition to increasing the graphitization degree. For both $\mathrm{Pt} @ \mathrm{SiO}_{2}-500$ and $\mathrm{Pt} @ \mathrm{SiO}_{2}-700$, the Pt 4f signals can be deconvoluted into two doublets assigned to $\mathrm{Pt}^{0}$ and $\mathrm{Pt}^{2+}$ states (Fig. $2 \mathbf{h}$ and $\mathbf{2 i}$ ), 
respectively, indicating that Pt NPs remained unchanged during thermal annealing ${ }^{20,45}$.

\subsection{Electrochemical tests of graphitic-shell-coated Pt catalysts}

The ORR performance of various Pt-T catalysts was first investigated using RDE in $\mathrm{O}_{2}$-saturated $0.1 \mathrm{M} \mathrm{HClO}_{4}$. For comparison, commercial Pt/C (Johnson Matthey, particle size: $\sim 3 \mathrm{~nm}$, Pt loading: $\sim 35 \mathrm{wt} . \%$ ) was tested as a standard (Supplementary Table 1 $)^{46}$. As expected, the as-synthesized, ligand-capped Pt NPs (Pt@OAm) loaded on KB were essentially inactive as indicated by linear sweep voltammetry (LSV, Fig. 3a). The ORR inactivity of Pt@OAm was presumably caused by the surface hydrocarbon ligands, which effectively block the accessibility of surface sites, consistent with previous results. ${ }^{25}$

Following the thermal annealing, all of the Pt-T catalysts demonstrated ORR activity, with the degree of activity varying depending on the annealing temperature that was used. Specifically, both Pt-500 and Pt-600 exhibited a relatively poor ORR activity, though the latter is slightly better in terms of the onset and half-wave potentials (Fig. 3a). Strikingly, when the annealing temperature reaches $700{ }^{\circ} \mathrm{C}$, the resulting Pt700 catalysts became highly active (Fig. 3a), with the half-wave potential higher than that of commercial Pt/C (0.902 V vs. $0.892 \mathrm{~V})$. Further increasing the annealing temperature to $800^{\circ} \mathrm{C}$ decreased the ORR activity. These results suggest that increasing the annealing temperature from 500 to $700{ }^{\circ} \mathrm{C}$ effectively activates Pt NPs. This annealing temperature-dependent ORR activity was also evidenced by cyclic voltammograms (CV). As shown in CV curves (Fig. 3b), Pt-700 showed the welldefined peaks of the monolayer hydrogen adsorption and desorption, whereas these 
features were barely observable for other three catalysts. Likewise, the ECSA of Pt-700 $\left(35.9 \mathrm{~m}^{2} \mathrm{~g}^{-1} \mathrm{Pt}\right)$ is much higher than that of Pt-500 $\left(3.1 \mathrm{~m}^{2} \mathrm{~g}^{-1} \mathrm{Pt}\right)$ and Pt-600 $\left(8.8 \mathrm{~m}^{2} \mathrm{~g}^{-1} \mathrm{Pt}\right)$ (despite all three having similar Pt particle sizes), indicating the greater exposure of surface sites as the annealing temperature increased from 500 to $700{ }^{\circ} \mathrm{C}^{21}$.
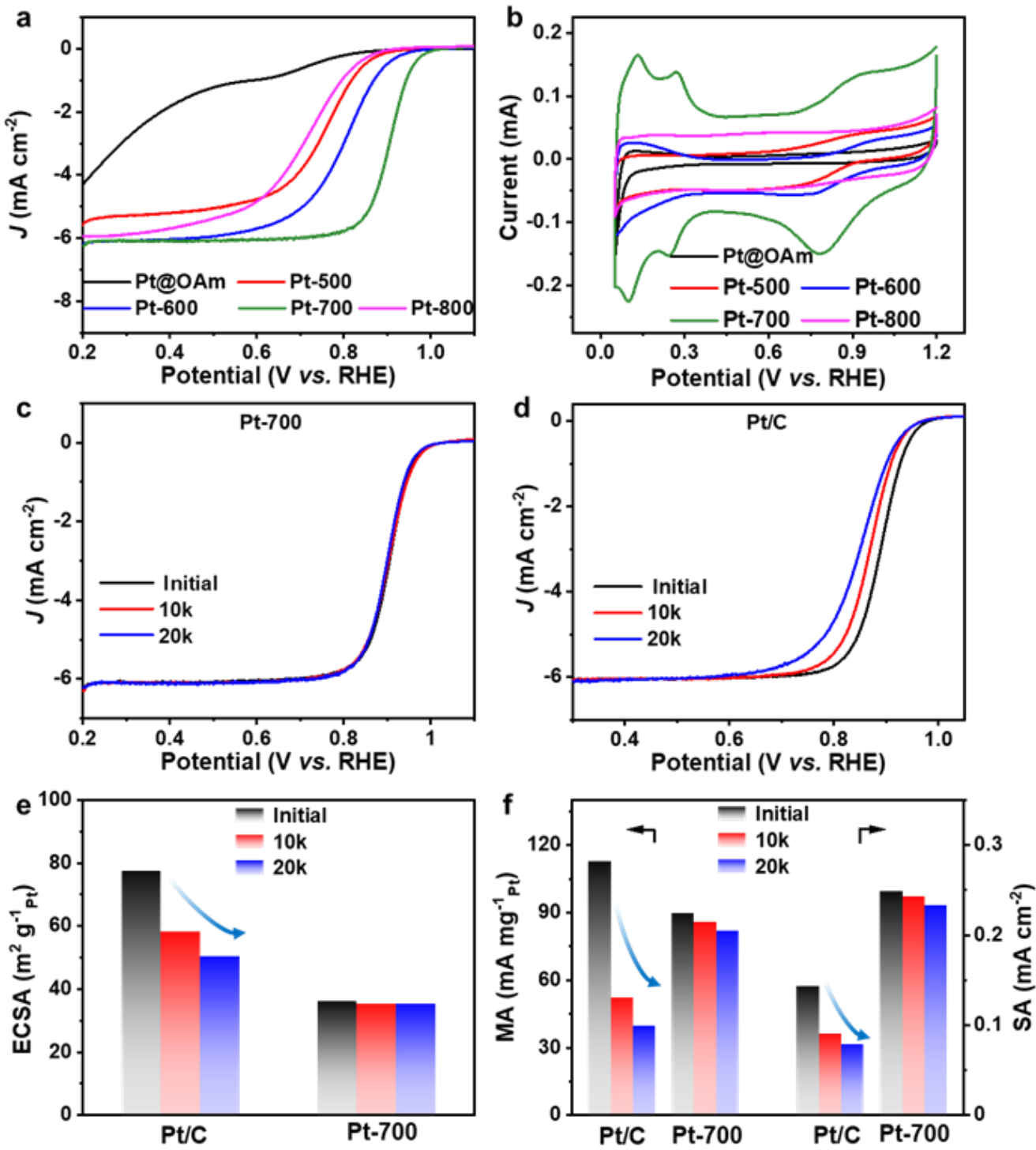

Fig. 3: (a) ORR polarization curves and (b) CV curves of Pt@OAm and various Pt-T catalysts. (c) ORR polarization curves of Pt-700 before and after ADT cycles. (d) ORR polarization curves of $\mathrm{Pt} / \mathrm{C}$ before and after ADT cycles. (e) Changes in ECSA for Pt/C and Pt-700 during the ADT. (f) Changes in MA (at 0.9 V) and SA for Pt/C and Pt-700 during the ADT. 
More importantly, in addition to the excellent ORR activity, Pt-700 also exhibited superior long-term stability. Fig. 3c shows the polarization curves of Pt-700 according to the number of accelerated durability test (ADT) cycles. The half-wave potential of Pt-700 was nearly unchanged after 20k ADT cycles, indicative of the negligible activity degradation, which was also verified by CV (Supplementary Fig. 4). The ECSA, mass activity (MA, at $0.9 \mathrm{~V}$ ), and specific activity (SA) of Pt-700 were largely retained as well after 20k ADT cycles (Fig. 3e and 3f), further confirming the negligible decrease of the accessible active sites ${ }^{47}$. In comparison, the half-wave potential of commercial $\mathrm{Pt} / \mathrm{C}$ was decreased by $\sim 50 \mathrm{mV}$ after 20k ADT cycles (Fig. 3d), along with an intensive degradation in ECSA, MA, and SA (Fig. 3e and 3f).

The poor stability of commercial $\mathrm{Pt} / \mathrm{C}$ is typical for Pt-based catalysts, which is presumably caused by the agglomeration and/or Ostwald ripening of Pt NPs during ORR. To further explore the degradation mechanism, we investigated the structural change of the same NPs during cycling by ex situ TEM by employing the positioning gold grids (see Supplementary information for details) ${ }^{48}$. TEM shows that after 20k ADT cycles some irregular large particles emerged for commercial Pt/C (Fig. 4a and 4b), whereas Pt-700 remained essentially unchanged with no particle agglomeration and detachment (Fig. $\mathbf{4 c}$ and $\mathbf{4 d}$ ). In addition, we also evaluated the dissolution of $\mathrm{Pt}$ NPs by analyzing the Pt species dissolved in electrolytes after 20k ADT cycles by ICPMS, which showed that the dissolved Pt content for Pt-700 was substantially lower than that for $\mathrm{Pt} / \mathrm{C}(0.232 \mathrm{ng} \text { vs. } 40 \mathrm{ng})^{49}$. The Pt particles from the $\mathrm{Pt} / \mathrm{C}$ catalyst are $\sim 1.7 \mathrm{x}$ smaller than the Pt particles from the Pt-700 catalyst, and it is well known that smaller 
Pt particles are more prone to dissolution than larger ones ${ }^{50-52}$. However, the antidissolution improvement of $\sim 170 \mathrm{x}$ far exceeds what would be expected based purely on differences in Pt particle size, and suggests that a further electronic effect may be largely responsible for the difference in Pt dissolution. Nonetheless, these results emphasize the great role of the ligand-derived graphitic shells in preventing migration, agglomeration, and dissolution of Pt NPs during the ADT.
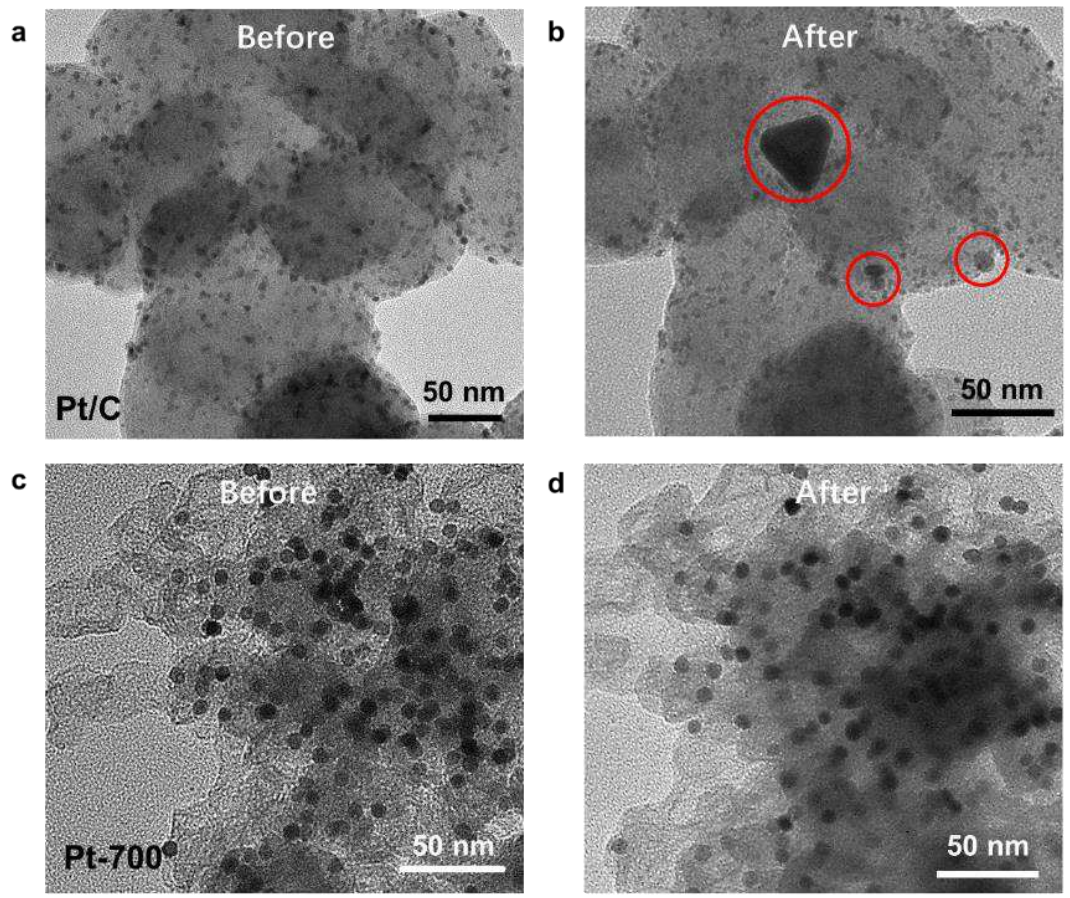

Fig. 4: Morphological variations of Pt/C (a) before and (b) after 20k ADT cycles. Red cycles in (b) indicate the large particles formed during the ADT cycles. Morphological variations of Pt-700 (c) before and (d) after 20k ADT cycles.

\subsection{Mechanistic understanding of the annealing temperature-dependent ORR} activity

Having established the importance of ligand carbonization for improving the ORR activity and stability of Pt NPs, we turn our attention to investigating the annealing temperature-dependent catalytic activity exhibited by Pt-T catalysts. As 
mentioned above, Pt-800 showed an inferior ORR activity, which is expected considering the severe agglomeration of Pt NPs at $800{ }^{\circ} \mathrm{C}$. However, the drastically different ORR activity exhibited by Pt-500, Pt-600, and Pt-700 is somewhat surprising, because these three catalysts comprise the same Pt NPs coated with carbon shells having a similar thickness (i.e., bilayer carbon) ${ }^{53}$. The fact that Pt-500 has a very small $\operatorname{ECSA}\left(\sim 3.1 \mathrm{~m}^{2} \mathrm{~g}^{-1} \mathrm{Pt}\right)$ despite no apparent change in Pt particle size (Fig. 1a) indicates that the carbon shell resulting from annealing at $500{ }^{\circ} \mathrm{C}$ is very dense in nature, which severely blocks the accessibility of surface sites despite its ultrathin thickness. Conversely, the enhanced ECSA and ORR activity exhibited by Pt-600 and Pt-700 suggests the accessibility of Pt NPs was gradually improved with the annealing temperature increasing from 500 to $700{ }^{\circ} \mathrm{C}$. Given the essentially unchanged carbon shell thickness, we speculate that the initially dense carbon shell undergoes structural reconstruction and becomes progressively porous with the increased annealing temperature, as illustrated in Scheme 1.

Since it is difficult to directly visualize the proposed porosity in carbon shells by HRTEM (Fig. 1e-g), we designed poisoning experiments to better reveal the subtle carbon-shell difference between various Pt-T catalysts ${ }^{20}$. Polystyrene with a terminal thiol group (denoted as PS-SH), with a molecular weight of 12600 (the molecular length of PS-SH is estimated to be $\sim 28 \mathrm{~nm})^{54}$, was synthesized as a molecular probe. The thiol group is a well-known deactivator of ORR due to its strong binding affinity to $\mathrm{Pt}^{55}$. The three catalysts (Pt/C, Pt-500 and Pt-700) were treated with PS-SH in a tetrahydrofuran (THF) solution for $12 \mathrm{~h}$. As reference, the small thiol-containing molecule, 
dodecanethiol $\left(\mathrm{C}_{12} \mathrm{H}_{25} \mathrm{SH}\right)$, was also used to treat catalysts under the same conditions. As expected, for $\mathrm{Pt} / \mathrm{C}$ without carbon coating, both $\mathrm{C}_{12} \mathrm{H}_{25} \mathrm{SH}$ and PS-SH can easily poison Pt NPs as indicated by the fully deactivated ORR activity (Fig. 5a). Likewise, both Pt-500 and Pt-700 were completely deactivated upon treatment with $\mathrm{C}_{12} \mathrm{H}_{25} \mathrm{SH}$ (Fig. 5b and 5c), indicating that their carbon shells are permeable to $\mathrm{C}_{12} \mathrm{H}_{25} \mathrm{SH}$ molecules under the aforementioned treatment conditions. In the case of poisoning with PS-SH, however, Pt-500 and Pt-700 showed quite different anti-deactivation behaviors. Specifically, Pt-500 largely retained the ORR activity after PS-SH treatment (Fig. 5b), indicating that the carbon shells are impermeable to the bulky PS-SH molecules. In contrast, treatment of Pt-700 with PS-SH led to an apparent degradation in the catalytic activity (Fig. 5c). This implies that the carbon shells of Pt-700 have wider porous channels compared to Pt-500, which allow the partial penetration of PS-SH molecules. These results not only qualitatively reveal the porosity difference of carbon shells between various catalysts, but also demonstrate that the porosity of the ligand-derived carbon shells, which is a key factor dictating the ORR activity of Pt NPs, can be tailored by simply controlling the thermal annealing temperature. It is likely that with the increasing of the annealing temperature the graphitic and rigid carbon shells can no longer maintain a complete and continuous spherical geometry due to the high curvature, with multiple discontinuous segments becoming favorable as depicted in Fig. 5d. Such fractures and defects could provide porous channels for accessing the encapsulated Pt NPs, which accounts for the high ORR activity exhibited by Pt-700. 

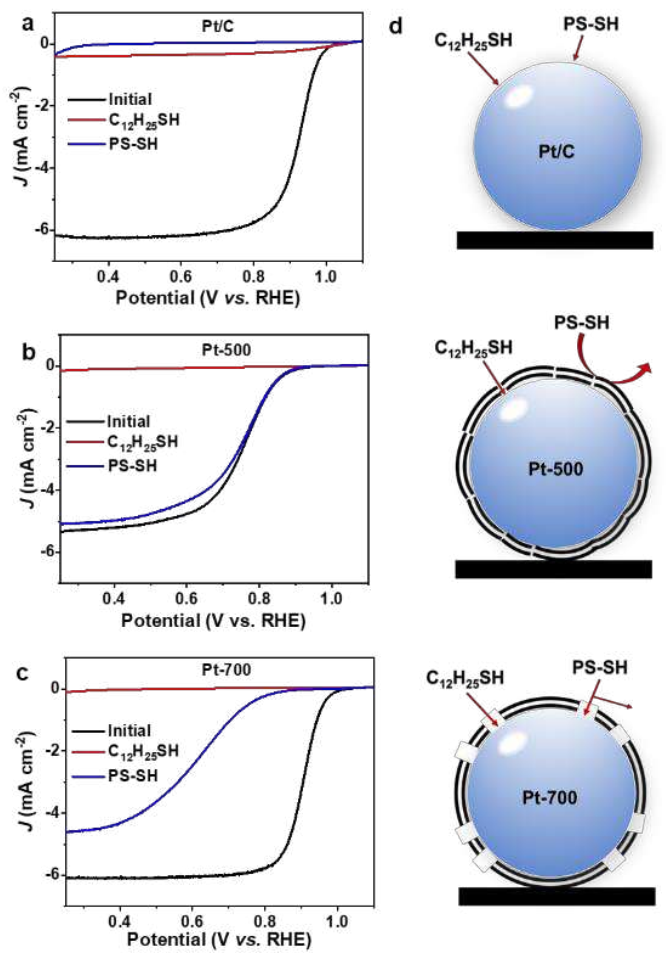

Fig. 5: ORR polarization curves of (a) Pt/C, (b) Pt-500, and (c) Pt-700 before and after treatment with $\mathrm{C}_{12} \mathrm{H}_{25} \mathrm{SH}$ and PS-SH. (d) Schematics of the surface accessibility of Pt/C, Pt-500, and Pt-700, respectively, by $\mathrm{C}_{12} \mathrm{H}_{25} \mathrm{SH}$ and PS-SH molecules.

\subsection{Membrane electrode assembly (MEA) tests}

To test the durability of the graphitic-shell-coated Pt catalysts under the realistic operating conditions for PEMFCs, MEAs were fabricated and put through a Ptdissolution ADT 20k cycles $^{56,57}$. As shown in Fig. 6a, the performance of the MEA with $\mathrm{Pt} / \mathrm{C}$ degraded rapidly with the increased ADT cycles, whereas the Pt-700 cell demonstrated an exceptional durability (Fig. 6b), consistent with RDE tests ${ }^{58}$. Interestingly, Pt-700 showed slightly improved performance after the first 5k ADT cycles (both under air and $100 \% \mathrm{O}_{2}$ ). While it may be anticipated that this was due to oxidation of the carbon shell leading to more exposed Pt $\operatorname{sites}^{18}$, there was no noticeable increase in ECSA following 5k cycles. Thus, the increase in performance is more likely 
a result of surface oxidation leading to enhanced proton transport within the catalyst layer. The variation of the maximum power density during the ADT was also compared. While the Pt-700 cell displayed a smaller initial maximum power density relative to $\mathrm{Pt} / \mathrm{C}$ due to the lower ECSA (Supplementary Table 1), Pt-700 could maintain a more stable power density, which started to exceed that of Pt/C after 10k ADT cycles (Fig. 6c). Furthermore, the Pt-700 cell exhibited a small voltage loss of only $11 \mathrm{mV}$ at an operating current density of $0.8 \mathrm{~A} / \mathrm{cm}^{2}$ after 20k ADT cycles (Fig. 6d), whereas the cell voltage of $\mathrm{Pt} / \mathrm{C}$ decreased by $75 \mathrm{mV}$ under the same cycling conditions. The polarization curves under $100 \% \mathrm{O}_{2}$ are also shown in Supplementary Fig. 5, which help to highlight that the performance loss is kinetic (as would be expected from this particular ADT) for both Pt-700 and $\mathrm{Pt} / \mathrm{C}$, and the superior durability of $\mathrm{Pt}-700 \mathrm{vs}$. $\mathrm{Pt} / \mathrm{C}$.
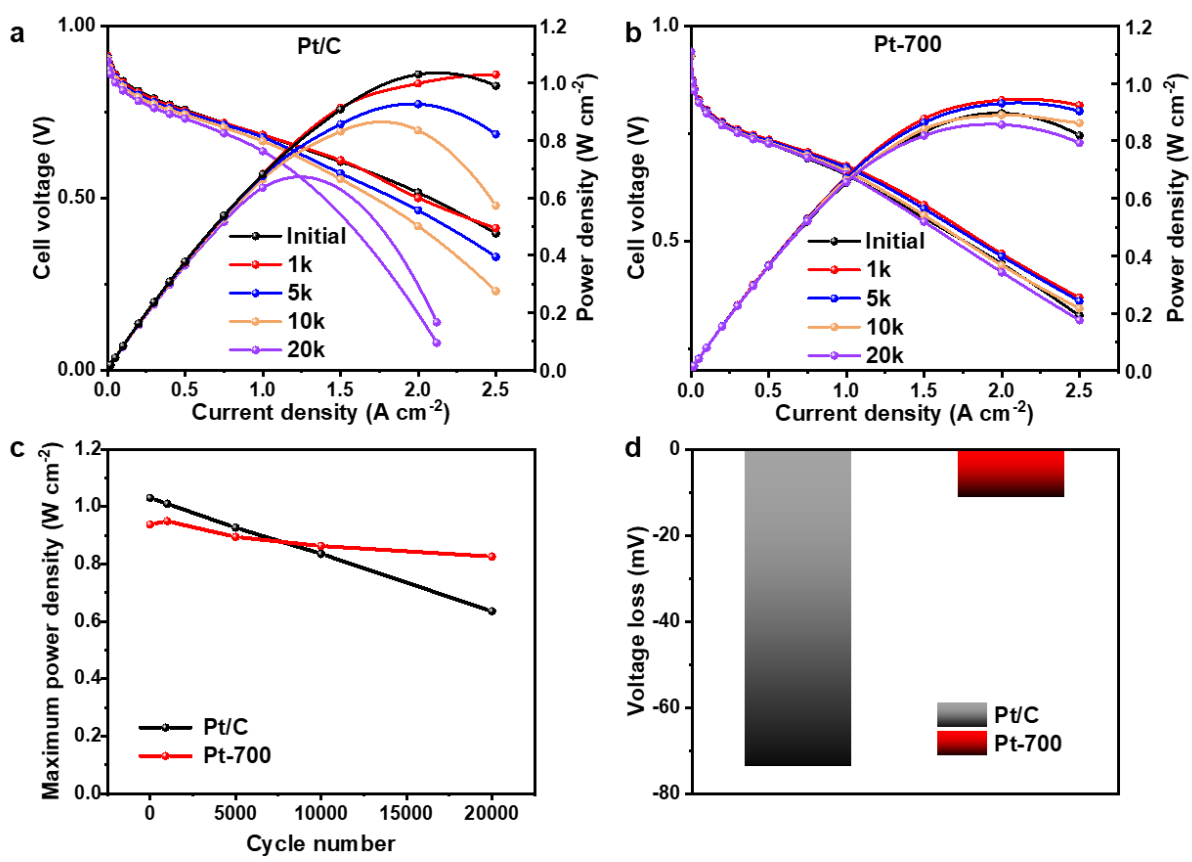

Fig. 6: Polarization curves of the MEAs with (a) Pt/C and (b) Pt-700 before and after ADT cycles. (c) Changes of the maximum power density with the ADT cycles for Pt/C and Pt-700 cells, respectively. (d) Voltage loss (at $0.8 \mathrm{~A} \mathrm{~cm}^{-2}$ ) after $20 \mathrm{k}$ cycles for Pt/C and Pt-700 cells, respectively. 


\subsection{Generality of the ligand carbonization approach}

It is well known that decreasing the size of Pt NPs will dramatically increase the ECSA, which is advantageous for enhancing the ORR activity ${ }^{52}$. However, as the particle size decreases below $\sim 3 \mathrm{~nm}$, the catalyst particles begin to demonstrate unfavorable ORR kinetics as a result of unfavorable crystal structures dominating the surface ('particle size effect'). Unfortunately, Pt particles of this size are also still prone to rapid dissolution ${ }^{50}$. This reality has historically meant that there is an unfortunate inverse relationship between activity and stability that must be balanced by MEA designers when selecting a catalyst. To determine whether the ligand carbonization strategy presented here can break this relationship, the OAm-capped Pt NPs with a diameter of $\sim 3 \mathrm{~nm}$ were synthesized (Supplementary Fig. 6a and 6b). Using the same protocol developed for $5 \mathrm{~nm}-\mathrm{Pt}$ NPs, we obtained $3 \mathrm{~nm}-\mathrm{Pt}-700$ catalysts by thermally treating $3 \mathrm{~nm}$-Pt NPs supported on KB (Pt loading: $\sim 20$ wt. $\%$ ) at $700{ }^{\circ} \mathrm{C}$ under $\mathrm{N}_{2}$ protection. Despite the decreased particle size, no apparent agglomeration of $3 \mathrm{~nm}-\mathrm{Pt}$ NPs was observed upon thermal annealing, as evidenced by TEM (Fig. 7a) and XRD (Supplementary Fig. 6c). HRTEM reveals that the $3 \mathrm{~nm}$-Pt NPs are homogeneously coated with approximately two graphic layers derived from the OAm ligands (Fig. 7a, inset). Importantly, these $3 \mathrm{~nm}-\mathrm{Pt}-700$ catalysts exhibited a high ORR activity and stability as indicated by the polarization curves (Fig. 7b) and CV (Supplementary Fig. 6d). As expected, the ECSA (Fig. 7c) of $3 \mathrm{~nm}-\mathrm{Pt}-700$ is much higher than that of its 5 nm-Pt counterpart $\left(66.8 \mathrm{~m}^{2} \mathrm{~g}^{-1} \mathrm{Pt}\right.$ vs. $35.9 \mathrm{~m}^{2} \mathrm{~g}^{-1} \mathrm{Pt}$, Supplementary Table 1), due to the smaller size of Pt NPs. Moreover, $3 \mathrm{~nm}-\mathrm{Pt}-700$ only showed small degradation in ECSA 
and MA (at $0.9 \mathrm{~V}$ ) after 20k ADT cycles (Fig. 7c). It is thus confirmed that our in situ ligand carbonization strategy is general and can be exploited to boost the ORR stability of highly active Pt catalysts, which could greatly expand the design abilities for commercial MEA developers.
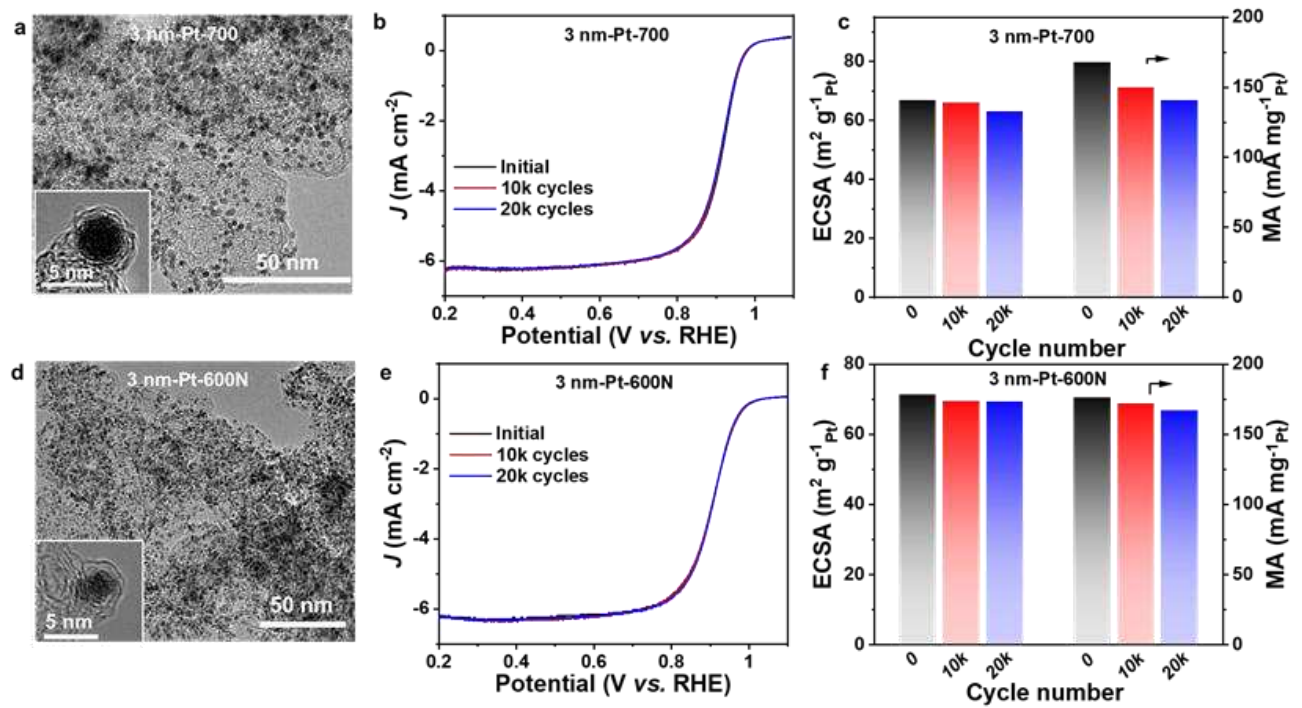

Fig. 7: (a) TEM and HRTEM (inset) images and (b) ORR polarization curves of $3 \mathrm{~nm}$ Pt-700 catalysts. (c) Changes of ECSA and MA (at $0.9 \mathrm{~V}$ ) for $3 \mathrm{~nm}-\mathrm{Pt}-700$ according to the number of ADT cycles. (d) TEM and HRTEM (inset) images and (e) ORR polarization curves of $3 \mathrm{~nm}-\mathrm{Pt}-600 \mathrm{~N}$ catalysts. (f) Changes of ECSA and MA (at $0.9 \mathrm{~V}$ ) for $3 \mathrm{~nm}-\mathrm{Pt}-600 \mathrm{~N}$ according to the number of ADT cycles.

It should be noted that increasing the Pt loading of $3 \mathrm{~nm}-\mathrm{Pt}$ NPs to $\sim 35 \mathrm{wt} . \%$ could lead to severe particle agglomeration when thermally treated at $700{ }^{\circ} \mathrm{C}$ (Supplementary Fig. 7), which is expected considering the ultrasmall particle size. Lowering the annealing temperature to $600{ }^{\circ} \mathrm{C}$ could mitigate the sintering problem (Supplementary Fig. 8a), yet the resulting $3 \mathrm{~nm}-\mathrm{Pt}-600$ catalyst showed a similarly poor ORR activity as its 5-nm counterpart (Supplementary Fig. 8b), presumably because of the dense nature of the carbon shells resulting from thermal annealing at 600 
${ }^{\circ} \mathrm{C}$. Thus, we introduced $\mathrm{N}$ atoms during thermal annealing to afford $\mathrm{N}$-doped carbon shells, as $\mathrm{N}$ doping has been demonstrated to be capable of enhancing the ORR activity of carbon-coated $\mathrm{Pt} \mathrm{NPs}^{59,60}$. N doping was realized by conducting thermal annealing at $600{ }^{\circ} \mathrm{C}$ in the presence of urea, yielding $3 \mathrm{~nm}-\mathrm{Pt}-600 \mathrm{~N}$ catalysts with an $\mathrm{N}$ content of $\sim 3.7$ at.\%. No particle aggregation was observed during $\mathrm{N}$ doping (Fig. 7d), and more importantly, the resulting $3 \mathrm{~nm}-\mathrm{Pt}-600 \mathrm{~N}$ showed a significantly improved ORR activity (Fig. 7e), while simultaneously maintaining the superior long-term stability (Fig. 7f). The enhanced ORR activity of $3 \mathrm{~nm}-\mathrm{Pt}-600 \mathrm{~N}$ relative to $3 \mathrm{~nm}-\mathrm{Pt}-600$ (Supplementary Fig. $8 \mathrm{~b}$ ) indicates the greater exposure of surface-active sites. We speculate that in addition to altering the electronic structure of $\mathrm{Pt}$ which favors the ORR, $\mathrm{N}$ doping also facilitates the widening of porous channels in carbon shells ${ }^{61}$. These results thus establish an alternative route of obtaining highly efficient ORR catalysts based on ultrasmall Pt NPs. In addition to Pt, this in situ ligand carbonization strategy is also applicable to alloy NPs. As shown in Supplementary Fig. 9, thermal annealing of PtPd NPs ( $\sim 4 \mathrm{~nm}$ in diameter) supported on $\mathrm{KB}$ at $700{ }^{\circ} \mathrm{C}$ produced graphitic-shell-coated PtPd catalysts with an excellent ORR activity and stability ${ }^{62}$.

Moreover, this ligand carbonization strategy can further be applied to improve the durability of commercial $\mathrm{Pt} / \mathrm{C}$ catalysts. Surface modification was realized by mixing $\mathrm{Pt} / \mathrm{C}$ with OAm ligands in isopropanol followed by stirring overnight. Considering the small size of Pt NPs $(\sim 3 \mathrm{~nm})$, subsequent ligand carbonization was conducted at 600 ${ }^{\circ} \mathrm{C}$ in the presence of urea to produce $\mathrm{Pt} / \mathrm{C}-600 \mathrm{~N}$ catalysts. TEM (Fig. 8a and 8b) and XRD (Supplementary Fig. 10) verify that the size of Pt NPs was unchanged upon 
annealing, indicative of the high sintering resistance of Pt NPs. Meanwhile, HRTEM reveals that the original bare Pt NPs was uniformly coated with bilayered graphitic shells derived from the OAm ligands (Fig. 8b, inset). The ECSA of Pt/C was reduced by $\sim 15 \%$ upon ligand carbonization $\left(77.4 \mathrm{~m}^{2} / \mathrm{g}_{\mathrm{Pt}} \mathrm{vs} .65 .8 \mathrm{~m}^{2} / \mathrm{g}_{\mathrm{Pt}}\right.$, Supplementary Table 1), indicating that over-coating Pt NPs with bilayered graphitic shells only blocked a fraction of surface sites ${ }^{63}$. Moreover, compared with pristine Pt/C (Fig. 3d), Pt/C-600N exhibited significantly improved stability as indicated by the negligible activity degradation after 20k ADT cycles (Fig. 8c and 8d). The substantially enhanced ORR durability was also manifested in the MEA tests (Fig. 8e), where the Pt/C-600N cell showed a voltage loss of only $13 \mathrm{mV}$ at $0.8 \mathrm{~A} / \mathrm{cm}^{2}$ after $20 \mathrm{k}$ ADT cycles (Fig. 8f). The percent ECSA loss of Pt/C-600N was also provided in Supplementary Fig. 11, where it is apparent that the graphitic shell greatly reduces the rate of loss in ECSA for both $\mathrm{Pt} / \mathrm{C}-600 \mathrm{~N}$ and Pt/C-700 vs. the untreated Pt/C.
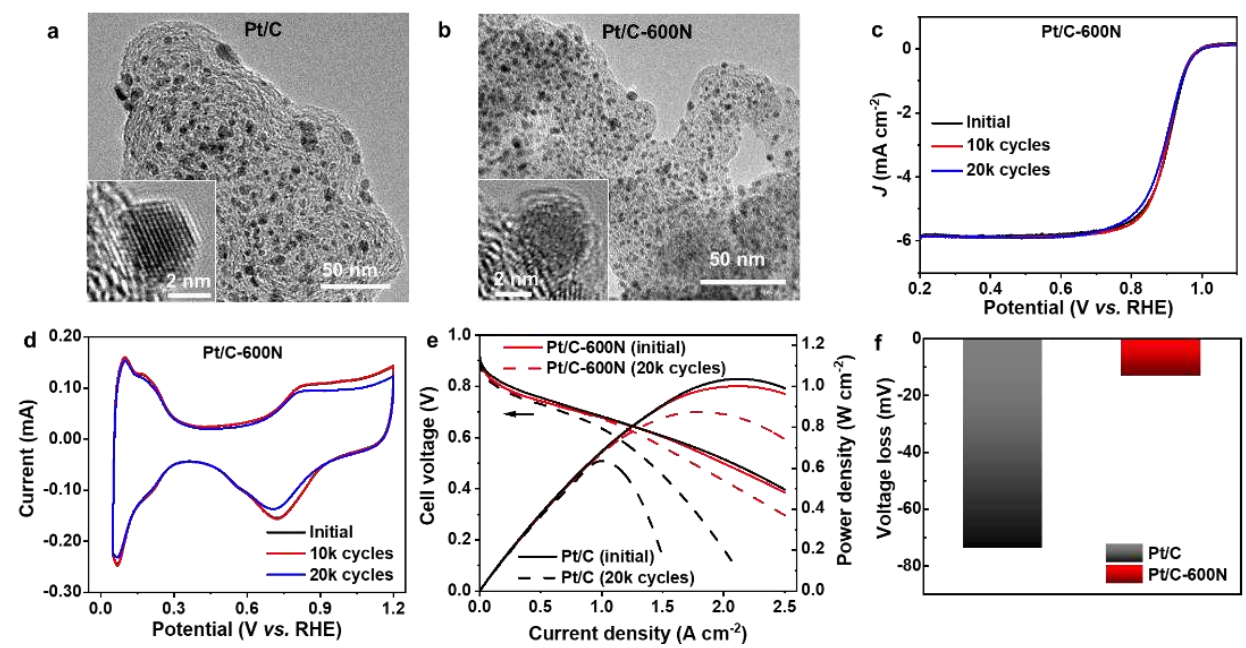

Fig. 8: TEM images of (a) $\mathrm{Pt} / \mathrm{C}$ and (b) $\mathrm{Pt} / \mathrm{C}-600 \mathrm{~N}$. Insets are the corresponding HRTEM images. (c) ORR polarization curves and (d) CV curves of Pt/C-600N. (e) Polarization curves of the MEAs with $\mathrm{Pt} / \mathrm{C}$ and $\mathrm{Pt} / \mathrm{C}-600 \mathrm{~N}$ before and after $20 \mathrm{k}$ cycles. (f) Voltage loss (at $0.8 \mathrm{~A} \mathrm{~cm}^{-2}$ ) after $20 \mathrm{k}$ cycles for $\mathrm{Pt} / \mathrm{C}$ and $\mathrm{Pt} / \mathrm{C}-600 \mathrm{~N}$ cells, 
respectively.

\section{Conclusion}

In this work, we have developed a facile and effective method for preparing stable graphitic-shell-coated Pt catalysts by harnessing the native ligands tethered to the surface of colloidal Pt NPs. Simple thermal annealing of Pt NPs converts the hydrocarbon ligands into uniform, bilayered graphitic shells, which are sufficiently robust to protect Pt NPs against migration, agglomeration, and dissolution while largely maintaining the accessibility of surface sites. The ORR activity of the resulting carbon-coated Pt catalysts depends strongly on the thermal annealing temperature, which dictates the microstructure of graphitic shells. In particular, the graphitic-shellcoated Pt catalysts resulting from thermal annealing at $700{ }^{\circ} \mathrm{C}$ show superior longterm durability to those of commercial $\mathrm{Pt} / \mathrm{C}$ catalysts. Importantly, this in situ ligand carbonization strategy is general and can also be applied to improve the stability of commercial $\mathrm{Pt} / \mathrm{C}$, thus opening a new route of developing highly durable ORR catalysts for PEMFCs.

\section{Methods}

\section{Synthesis of colloidal Pt and PtPd NPs.}

Monodisperse Pt NPs with a diameter of $\sim 5 \mathrm{~nm}$ were synthesized according to a literature method with slight modifications ${ }^{33}$. A precursor mixture was prepared by dissolving $0.16 \mathrm{~g}$ of $\mathrm{Pt}(\mathrm{acac})_{2}$ in $20 \mathrm{~mL}$ of benzyl ether, $14.72 \mathrm{~mL}$ of OAm, and $2.5 \mathrm{~mL}$ of OA. The mixture was degassed under vacuum at $120{ }^{\circ} \mathrm{C}$ for $30 \mathrm{~min}$, and was then 
heated to $160{ }^{\circ} \mathrm{C}$ under a $\mathrm{N}_{2}$ atmosphere, into which an additive solution of manganese carbonyl ( $0.16 \mathrm{~g}$ in $0.5 \mathrm{~mL}$ of chloroform) was injected. The reaction mixture was then heated to $200{ }^{\circ} \mathrm{C}$ and kept at this temperature for $30 \mathrm{~min}$. The as-synthesized Pt NPs were precipitated from the crude reaction mixture by addition of ethanol. After centrifugation, the precipitated NPs were re-dispersed in chloroform with a concentration of $10 \mathrm{mg} \mathrm{mL}^{-1}$.

For the synthesis of monodisperse Pt NPs with a diameter of $\sim 3 \mathrm{~nm}, 50 \mathrm{mg}$ of $\mathrm{Pt}(\mathrm{acac})_{2}$ and $10 \mathrm{~mL}$ of $\mathrm{OAm}$ were added into a three-neck flask with vigorous stirring. After degassing, the reaction mixture was heated to $100{ }^{\circ} \mathrm{C}$. After that, a mixture containing $0.2 \mathrm{~g}$ of borane tert-butylamine complex and $5 \mathrm{~mL}$ of OAm was quickly injected into the flask. Subsequently, the mixture was heated up to $120^{\circ} \mathrm{C}$ and kept for $1 \mathrm{~h}$. The purification of $3 \mathrm{~nm}-\mathrm{Pt}$ NPs was conducted similarly as $5 \mathrm{~nm}-\mathrm{Pt}$ NPs mentioned above.

Monodisperse PtPd NPs ( $\sim 4 \mathrm{~nm}$ in diameter) were obtained by a literature method with minor modifications ${ }^{64}$. Briefly, $16.2 \mathrm{mg}$ of $\operatorname{Pt}(\mathrm{acac})_{2}, 12.8 \mathrm{mg}$ of $\operatorname{Pd}(\mathrm{acac})_{2}, 825$ $\mu \mathrm{L}$ of OAm, and $400 \mu \mathrm{L}$ of OA were added to a three-neck flask together with $20 \mathrm{~mL}$ of ODE as solvent. The mixture was evacuated for $15 \mathrm{~min}$ and then $140 \mu \mathrm{L}$ of TOP was added. After degassing for another $60 \mathrm{~min}$ at $50{ }^{\circ} \mathrm{C}$, the reaction mixture was heated to $320{ }^{\circ} \mathrm{C}$ with $\mathrm{N}_{2}$ protection under vigorous stirring. After 30 min of reaction, the solution was allowed to cool to room temperature. Subsequent purification of PtPd NPs was conducted similarly as Pt NPs mentioned above.

Synthesis of graphitic-shell-coated Pt catalysts. 
A chloroform solution $(2 \mathrm{~mL})$ containing the as-synthesized Pt NPs was mixed with $15 \mathrm{mg}$ of $\mathrm{KB}$ followed by sonication for $30 \mathrm{~min}$. After drying at $60^{\circ} \mathrm{C}$ overnight, the $\mathrm{Pt} @ \mathrm{~KB}$ powder was annealed at $500{ }^{\circ} \mathrm{C}$ in a $\mathrm{N}_{2}$ atmosphere for $1 \mathrm{~h}$ to induce the ligand carbonization. Graphitic-shell-coated Pt catalysts were obtained upon further annealing at different temperatures $\left(500-800^{\circ} \mathrm{C}\right)$ for another $1 \mathrm{~h}$. Graphitic-shell-coated PtPd catalysts were obtained by a similar procedure, with the final thermal annealing temperature of $700{ }^{\circ} \mathrm{C}$.

\section{Modification of commercial $\mathbf{P t} / \mathrm{C}$ catalysts.}

Commercial Pt/C catalysts, $200 \mu \mathrm{L}$ of OAm, and $10 \mathrm{~mL}$ of isopropanol were mixed in a vial followed by stirring overnight, during which OAm ligands were attached to Pt NPs. The OAm-modified Pt/C was collected by centrifugation and was then heated at $500{ }^{\circ} \mathrm{C}$ for $1 \mathrm{~h}$ to carbonize the OAm ligands. Pt/C-600N catalysts were obtained by uniformly mixing urea with $\mathrm{Pt} / \mathrm{C}$ with a mass ratio of 10:1 followed by annealing in a $\mathrm{N}_{2}$ atmosphere at $600{ }^{\circ} \mathrm{C}$ for another $1 \mathrm{~h}$.

\section{Data availability}

All relevant data that support the findings of this study are available within the article and its Supplementary Materials.

\section{References}

1. Ojemaye, M. O., Okoh, A. I. Global research direction on Pt and Pt based electrocatalysts for fuel cells application between 1990 and 2019: A bibliometric analysis. Int. J. Hydrog. Energy 45, 15783-15796 (2021).

2. Wang, S., Jiang, S. P. Prospects of fuel cell technologies. Natl. Sci. Rev. 4, 163-166 
(2017).

3. Lee, Y. M. Fuel cells: Operating flexibly. Nat. Energy 1, 16136 (2016).

4. Nie, Y., Li, L., Wei, Z. Recent advancements in Pt and Pt-free catalysts for oxygen reduction reaction. Chem. Soc. Rev. 44, 2168-2201 (2015).

5. Wan, S., et al. Co/N-doped carbon nanotube arrays grown on 2D MOFs-derived matrix for boosting the oxygen reduction reaction in alkaline and acidic media. Chin. Chem. Lett. 32, 816-821 (2021).

6. Nørskov, J. K., et al. Origin of the overpotential for oxygen reduction at a fuel-cell cathode. J. Phys. Chem. B 108, 17886-17892 (2004).

7. Mustain, W. E., Chatenet, M., Page, M., Kim, Y. S. Durability challenges of anion exchange membrane fuel cells. Energy Environ. Sci. 13, 2805-2838 (2020).

8. Zhang, J., Yuan, Y., Gao, L., Zeng, G., Li, M., Huang, H. Stabilizing Pt-based electrocatalysts for oxygen reduction reaction: Fundamental understanding and design strategies. Adv. Mater. 33, 2006494 (2021).

9. Wang, Y. -J., Zhao, N., Fang, B., Li, H., Bi, X. T., Wang, H. Carbon-supported Ptbased alloy electrocatalysts for the oxygen reduction reaction in polymer electrolyte membrane fuel cells: Particle size, shape, and composition manipulation and their impact to activity. Chem. Rev. 115, 3433-3467 (2015).

10. Parthasarathy, P., Virkar, A. V. Electrochemical Ostwald ripening of Pt and Ag catalysts supported on carbon. J. Power Sources 234, 82-90 (2013).

11. Yu, K., et al. Degradation mechanisms of platinum nanoparticle catalysts in proton exchange membrane fuel cells: The role of particle size. Chem. Mater. 26, 5540- 
5548 (2014).

12. Li, X., et al. Atomic-level construction of tensile-strained PdFe alloy surface toward highly efficient oxygen reduction electrocatalysis. Nano Lett. 20, 14031409 (2020).

13. Qiao, Z., et al. 3D porous graphitic nanocarbon for enhancing the performance and durability of Pt catalysts: A balance between graphitization and hierarchical porosity. Energy Environ. Sci. 12, 2830-2841 (2019).

14. Gohl, D., et al. Engineering stable electrocatalysts by synergistic stabilization between carbide cores and Pt shells. Nat. Mater. 19, 287-291 (2020).

15. Kim, J., Hong, Y., Lee, K., Kim, J. Y. Highly stable Pt-based ternary systems for oxygen reduction reaction in acidic electrolytes. Adv. Energy Mater., 10, 2002049 (2020).

16. Chang, I., Ji, S., Park, J., Lee, M. H., Cha, S. W. Ultrathin YSZ coating on Pt cathode for high thermal stability and enhanced oxygen reduction reaction activity. Adv. Energy Mater. 5, 1402251 (2015).

17. Takenaka, S., Goto, M., Masuda, Y., Emura, S., Kishida, M. Improvement in the durability of carbon black-supported Pt cathode catalysts by silica-coating for use in PEFCs. Int. J. Hydrog. Energy 43, 7473-7482 (2018).

18. Karuppannan, M., et al. A highly durable carbon-nanofiber-supported $\mathrm{Pt}-\mathrm{C}$ coreshell cathode catalyst for ultra-low Pt loading proton exchange membrane fuel cells: Facile carbon encapsulation. Energy Environ. Sci. 12, 2820-2829 (2019).

19. Cao, Z., et al. A new catalytic system with balanced activity and durability toward 
oxygen reduction. Chem CatChem 12, 4817-4824 (2020).

20. Chung, D. Y., et al. Highly durable and active PtFe nanocatalyst for electrochemical oxygen reduction reaction. J. Am. Chem. Soc. 137, 15478-15485 (2015).

21. Guo, L., Jiang, W. -J., Zhang, Y., Hu, J. -S., Wei, Z. -D., Wan, L. -J. Embedding Pt nanocrystals in $\mathrm{N}$-doped porous carbon/carbon nanotubes toward highly stable electrocatalysts for the oxygen reduction reaction. ACS Catal. 5, 2903-2909 (2015).

22. Lee, D., et al. Variations in electrochemical characteristics of a platinum catalyst enwrapped by a carbon shell according to carbon layer thickness. ACS Appl. Energy Mater. 5, 596-603 (2022).

23. Muzzio, M., Li, J., Yin, Z., Delahunty, I. M., Xie, J., Sun, S. Monodisperse nanoparticles for catalysis and nanomedicine. Nanoscale 11, 18946-18967 (2019).

24. Kang, Y., et al. Design of Pt-Pd binary superlattices exploiting shape effects and synergistic effects for oxygen reduction reactions. J. Am. Chem. Soc. 135, 42-45 (2013).

25. Dong, A., et al. A generalized ligand-exchange strategy enabling sequential surface functionalization of colloidal nanocrystals. J. Am. Chem. Soc. 133, 998-1006 (2011).

26. Liu, Y., Li, D., Stamenkovic, V. R., Soled, S., Henao, J. D., Sun, S. Synthesis of $\mathrm{Pt}_{3} \mathrm{Sn}$ alloy nanoparticles and their catalysis for electro-oxidation of $\mathrm{CO}$ and methanol. ACS Catal. 1, 1719-1723 (2011).

27. Zhao, Q., Li, H., Zhang, X., Yu, S., Wang, S., Sun, G. Platinum in-situ catalytic 
oleylamine combustion removal process for carbon supported platinum nanoparticles. J. Energy Chem. 41, 120-125 (2020).

28. Humphrey, J. J., Sadasivan, S., Plana, D., Celorrio, V., Tooze, R. A., Fermin, D. J. Surface activation of Pt nanoparticles synthesized by "hot injection" in the presence of oleylamine. Chemistry: Eur. J. 21, 12694-12701 (2015).

29. Rossi, L. M., Fiorio, J. L., Garcia, M. A. S., Ferraz, C. P. The role and fate of capping ligands in colloidally prepared metal nanoparticle catalysts. Dalton Trans. 47, 5889-5915 (2018).

30. Mazumder, V., Sun, S. Oleylamine-mediated synthesis of Pd nanoparticles for catalytic formic acid oxidation. J. Am. Chem. Soc. 131, 4588-4589 (2009).

31. Zhu, H., Zhang, S., Guo, S., Su, D., Sun, S. Synthetic control of FePtM nanorods $(\mathrm{M}=\mathrm{Cu}, \mathrm{Ni})$ to enhance the oxygen reduction reaction. J. Am. Chem. Soc. 135, 7130-7133 (2013).

32. Lu, L., et al. Robust removal of ligands from noble metal nanoparticles by electrochemical strategies. ACS Catal. 8, 8484-8492 (2018).

33. Kang, Y., et al. Shape-controlled synthesis of Pt nanocrystals: The role of metal carbonyls. ACS Nano 7, 645-653 (2013).

34. Zou, J., Wang, B., Zhu, B., Yang, Y., Han, W., Dong, A. Fe, N, S-codoped carbon frameworks derived from nanocrystal superlattices towards enhanced oxygen reduction activity. Nano Converg. 6, 4 (2019).

35. Kim, Y., Jeffery, A. A., Min, J., Jung, N. Modulating catalytic activity and durability of $\mathrm{PtFe}$ alloy catalysts for oxygen reduction reaction through controlled 
carbon shell formation. Nanomaterials 9, 1491 (2019).

36. Holzwarth, U., Gibson, N. The Scherrer equation versus the 'Debye-Scherrer equation'. Nat. Nanotechnol. 6, 534-534 (2011).

37. Xue, Y., et al. N-doped carbon shell encapsulated PtZn intermetallic nanoparticles as highly efficient catalysts for fuel cells. Nano Res. 12, 2490-2497 (2019).

38. Tong, X., et al. Ultrathin carbon-coated Pt/carbon nanotubes: A highly durable electrocatalyst for oxygen reduction. Chem. Mater. 29, 9579-9587 (2017).

39. Mathur, R. B., Chatterjee, S., Singh, B. P. Growth of carbon nanotubes on carbon fiber substrates to produce hybrid/phenolic composites with improved mechanical properties. Compos. Sci. Technol. 68, 1608-1615 (2008).

40. Xiao, F., et al. Impact of heat treatment on the electrochemical properties of carbonsupported octahedral Pt-Ni nanoparticles. ACS Catal. 9, 11189-11198 (2019).

41. Kuznetsova, A., et al. Oxygen-containing functional groups on single-wall carbon nanotubes: NEXAFS and vibrational spectroscopic studies. J. Am. Chem. Soc. 123, 10699-10704 (2001)

42. Gago, S., et al. Synthesis, characterization and catalytic studies of bis(chloro)dioxomolybdenum(VI)-chiral diamine complexes. J. Mol. Catal. A Chem. 236, 1-6 (2005).

43. Geng, D., et al. Nitrogen doping effects on the structure of graphene. Appl. Surf. Sci. 257, 9193-9198 (2011).

44. Chen, Y., et al. Nitrogen doping effects on carbon nanotubes and the origin of the enhanced electrocatalytic activity of supported Pt for proton-exchange membrane 
fuel cells. J. Phys. Chem. C 115, 3769-3776 (2011).

45. Takenaka, S., Miyamoto, H., Utsunomiya, Y., Matsune, H., Kishida, M. Catalytic activity of highly durable Pt/CNT catalysts covered with hydrophobic silica layers for the oxygen reduction reaction in PEFCs. J. Phys. Chem. C 118, 774-783 (2014).

46. Liu, J., et al. High performance platinum single atom electrocatalyst for oxygen reduction reaction. Nat. Commun. 8, 15938 (2017).

47. Chen, S., et al. Nanostructured polyaniline-decorated Pt/C@PANI core-shell catalyst with enhanced durability and activity. J. Am. Chem. Soc. 134, 13252-13255 (2012).

48. Meier, J. C., et al. Degradation mechanisms of $\mathrm{Pt} / \mathrm{C}$ fuel cell catalysts under simulated start-stop conditions. ACS Catal. 2, 832-843 (2012).

49. Lin, G., et al. Suppressing dissolution of Pt-based electrocatalysts through the electronic metal-support interaction. Adv. Energy Mater. 11, 2101050 (2021).

50. Holby, E. F., Sheng, W., Shao-Horn, Y., Morgan, D. Pt nanoparticle stability in PEM fuel cells: Influence of particle size distribution and crossover hydrogen. Energy Environ. Sci. 2, 865-871 (2009).

51. Mukerjee, S. Particle size and structural effects in platinum electrocatalysis. J. Appl. Electrochem. 20, 537-548 (1990).

52. Xu, Z., Zhang, H., Zhong, H., Lu, Q., Wang, Y., Su, D. Effect of particle size on the activity and durability of the $\mathrm{Pt} / \mathrm{C}$ electrocatalyst for proton exchange membrane fuel cells. Appl. Catal. B 111-112, 264-270 (2012).

53. Kim, Y., et al. A target-customized carbon shell structure of carbon-encapsulated 
metal nanoparticles for fuel cell applications. J. Mater. Chem. A 9, 24480-24487 (2021).

54. Zhou, Z., Yan, D. Configurational-conformational statistics of stereoirregular polystyrene. Macromol. Theory Simul. 5, 939-945 (1996).

55. Genorio, B., Subbaraman, R., Strmcnik, D., Tripkovic, D., Stamenkovic, V. R., Markovic, N. M. Tailoring the selectivity and stability of chemically modified platinum nanocatalysts to design highly durable anodes for PEM fuel cells. Angew. Chem. Int. Ed. Engl. 50, 5468-5472 (2011).

56. Fan, J., et al. Bridging the gap between highly active oxygen reduction reaction catalysts and effective catalyst layers for proton exchange membrane fuel cells. Nat. Energy 6, 475-486 (2021).

57. Ahn, C. -Y., et al. Differences in the electrochemical performance of Pt-based catalysts used for polymer electrolyte membrane fuel cells in liquid half- and fullcells. Chem. Rev. 121, 15075-15140 (2021).

58. Kodama, K., Nagai, T., Kuwaki, A., Jinnouchi, R., Morimoto, Y. Challenges in applying highly active Pt-based nanostructured catalysts for oxygen reduction reactions to fuel cell vehicles. Nat. Nanotechnol. 16, 140-147 (2021).

59. Ramírez-Pérez, A. C., Quílez-Bermejo, J., Sieben, J. M., Morallón, E., CazorlaAmorós, D. Effect of nitrogen-functional groups on the ORR activity of activated carbon fiber-polypyrrole-based electrodes. Electrocatalysis 9, 697-705 (2018).

60. Zhou, S., Deng, S., Wang, Z., Liao, W., Chen, M., Wang, Q. Pt/C decorated with $\mathrm{N}$-doped carbon layers as a highly durable electrocatalyst for the oxygen reduction 
reaction. Energy Fuels 35, 20300-20308 (2021).

61. Hu, E., Yu, X. -Y., Chen, F., Wu, Y., Hu, Y., Lou, X. W. Graphene layers-wrapped $\mathrm{Fe} / \mathrm{Fe}_{5} \mathrm{C}_{2}$ nanoparticles supported on $\mathrm{N}$-doped graphene nanosheets for highly efficient oxygen reduction. Adv. Energy Mater. 8, 1702476 (2018).

62. Kongkanand, A., Subramanian, N. P., Yu, Y., Liu, Z., Igarashi, H., Muller, D. A. Achieving high-power PEM fuel cell performance with an ultralow-Pt-content core-shell catalyst. ACS Catal. 6, 1578-1583 (2016).

63. Hu, Y., et al. A low-temperature carbon encapsulation strategy for stable and poisoning-tolerant electrocatalysts. Small Methods 5, 2100937 (2021).

64. Goodman, E. D., et al. Uniform $\mathrm{Pt} / \mathrm{Pd}$ bimetallic nanocrystals demonstrate platinum effect on palladium methane combustion activity and stability. ACS Catal. 7, 4372-4380 (2017)

\section{Competing interests}

The authors declare no competing financial interests.

\section{Additional information}

Supplementary Information including supplementary methods, figures, and tables can be found with this article online. 


\section{Supplementary Files}

This is a list of supplementary files associated with this preprint. Click to download.

- Supplementaryinformation.pdf 